\title{
Matérián
}

ISSN 1517-7076

Revista Matéria, v. 11, n. 1, pp. 24 - 29, 2006

http://www.materia.coppe.ufrj.br/sarra/artigos/artigo10673

\section{Influência da Dureza dos Discos Abrasivos no Corte de Materiais Dúcteis}

\author{
E. C. BIANCHI ${ }^{1}$, E. J. SILVA ${ }^{2}$, T. V. FRANÇA ${ }^{1}$, C. E. SILVA JUNIOR ${ }^{1}$, I. D. VALARELLI ${ }^{1}$ \\ ${ }^{1}$ Universidade Estadual Paulista - UNESP - Campus de Bauru. Dept ${ }^{\mathrm{o}}$. de Eng ${ }^{\mathrm{a}}$. Mecânica, Av. Luiz Edmundo \\ Carrijo Coube, s/n., CxPostal 473, CEP 17033-360, Bauru, SP, Brasil. \\ e-mail: bianchi@feb.unesp.br, valareli@feb.unesp.br, thiagovf@feb.unesp.br, cesilvaj@gmail.com \\ ${ }^{2}$ Escola de Engenharia de São Carlos-EESC-USP. Dept ${ }^{\circ}$. de Eng ${ }^{\mathrm{a}}$. de Produção, Av. Trabalhador São \\ Carlense, 400, CEP 13566-590, São Carlos, SP, Brasil. \\ e-mail: eraldojs@sc.usp.br
}

\section{RESUMO}

O corte de materiais por disco abrasivo é um dos processos que apresentam as melhores características de economia, eficiência e rapidez sendo muito utilizado no meio industrial. Fatores como porcentagens e homogeneidade da mistura dos componentes, tamanho, forma (abrasividade), tenacidade e dureza dos grãos abrasivos, tipos de ligantes e de abrasivos, velocidade de corte e velocidade de mergulho influenciam na segurança, no desempenho e comportamento da operação.

Este trabalho apresenta um estudo sobre a influência da dureza dos discos abrasivos no desempenho do processo de corte em operações do tipo remoção a seco. O aumento da dureza dos discos propiciou um aumento da força tangencial de corte e da relação $\mathrm{G}$, devido à mais forte ligação entre o grão e o ligante no compósito. Os resultados mostram que a dureza dos discos abrasivos afeta a economia, pois influencia na vida útil dos discos abrasivos em termos de números de cortes proporcionados; a produtividade, pois está relacionada com o número de trocas de discos desgastados; os esforços necessários para a operação, pois estão relacionados com as forças tangenciais de corte.

Palavras chaves: Discos abrasivos, dureza, materiais dúcteis.

\section{Influence of Abrasive Discs Hardness on Cutting Performance of Ductile Materials}

\section{ABSTRACT}

The cutting of materials by abrasive discs is one of the processes that present the best characteristics of economy, efficiency and speed, thereby being very used in the industrial way. Factors as percentages and homogeneity of the mixture's components, size, shape (abrasive strength), toughness and hardness of the abrasive grains, types of binder and materials, disc speed and cutting speed affect the safety, performance and behavior of the cutting operation.

This work presents a study about the influence of abrasive disks hardness on their performance to cut-off ductile materials without cooling. The increase of the hardness of the disks resulted in an increase of the tangential cutting force and $\mathrm{G}$ ratio, due to stronger bonding between the abrasive particles and the binder in the composite. The results show that the hardness of the abrasive discs affects the economy, because it influences the useful life of the abrasive discs (the numbers cuts provided); the productivity because it determines the number of replaced discs; the necessary efforts for the operation because it is related with the tangential cutting force.

Keywords: Abrasive discs, hardness, ductile materials.

\section{INTRODUÇÃO}

Nos processos de corte com disco abrasivo, a dureza deste tem grande influência sobre sua vida útil. Um disco com maior dureza tende a reter mais o grão abrasivo. Com o conseqüente desgaste do grão, há perda da sua capacidade de remoção de material, as forças de corte elevam-se e o calor gerado pelo atrito entre o grão e a peça também aumenta. Caso o grão tenha friabilidade (capacidade em gerar novas arestas de corte quando fraturado) elevada, o crescimento da força de corte se dá de modo mais lento, uma vez que com 
esse aumento o grão passa a ser submetido a maior esforço e acaba fraturando-se e formando novas arestas. Isto se repete até que a parte exposta do abrasivo não seja suficiente para que ocorra a fratura, provocando o arredondamento do topo do grão e o conseqüente cegamento do disco abrasivo.

Já em um disco com menor grau de dureza, o processo descrito acima dificilmente ocorre. O grão abrasivo, à medida que se desgasta e provoca uma elevação nas forças de corte, tende a ser arrancado do disco. Como a resistência oferecida pelo ligante é baixa, o grão abrasivo se desprende (às vezes inteiro) e permite a ação de um novo grão abrasivo, num processo chamado de auto-afiação.

Segundo Bianchi et al. [1], não existem critérios consistentes para utilização de discos abrasivos no meio industrial, como na usinagem com ferramentas de arestas cortantes de geometria definida. Assim, os usuários utilizam discos abrasivos baseados em experiências pessoais, sem critério definido, e freqüentemente desprezam os aspectos de segurança inerentes ao processo.

Segundo König [3] , entende-se como sendo dureza de um disco abrasivo a resistência que este oferece à remoção de grãos abrasivos da sua superfície de corte, que depende basicamente da resistência de ligação entre o ligante e o grão e da resistência dos elos de ligação entre os grãos.

Para Nussbaum \& Dicastilho [5], a dureza depende da força e da tenacidade com que os grãos estão ligados ao corpo do disco, que é constituído por outros grãos ligados. A heterogeneidade e a presença de porosidade nos discos (dependendo da proporção dos poros) influenciam na dureza do disco abrasivo. Os poros têm a função de diminuir a temperatura na zona de contato disco/peça e de atuar como espaço para o alojamento dos cavacos.

Aparentemente, a dureza também depende da friabilidade e do tamanho do grão abrasivo. Quanto maior for o tamanho do grão abrasivo, ou quanto maior for sua friabilidade, maior é a facilidade em fraturalo, sugerindo um menor grau de dureza para o disco abrasivo.

A função de manter o grão em sua posição só é preenchida quando o ligante satisfaz as seguintes exigências: 1) o material do ligante deve ser o suficientemente resistente; 2) o ligante deve formar pontes entre os grãos com seção transversal suficientemente grande e 3) entre o grão abrasivo e o ligante deve existir uma energia de ligação suficientemente elevada para garantir a fixação do grão.

Enquanto que a primeira e a terceira propriedade são obtidas pela seleção do disco abrasivo e pelo processo de fabricação, a segunda propriedade é apenas obtida pela relação volumétrica entre os materiais de composição da ferramenta abrasiva [3]. Assim, segundo Malkin [4], se for descartada a possibilidade de adições de materiais de enchimento, a ferramenta abrasiva pode ser considerada como um sistema de três fases, constituído de grãos abrasivos, meio ligante e porosidades, determinado pela equação 1:

$$
V G \%+V L \%+V P \%=100 \%(V)
$$

De acordo com König [3] , para as variações das parcelas dos volumes, existem limites que por um lado são determinados pelas exigências de resistência ao disco abrasivo, e por outro lado, pelas próprias características de fabricação do disco. A título de exemplo, os limites para cada parcela para o caso de rebolos são: grãos abrasivos: 68 a 40\%; ligante: 24 a 5\% e poros: 55 a 17\% [3].

É através desse método que se define a estrutura do disco abrasivo. Entende-se por estrutura como sendo o volume percentual de abrasivo que é adicionado ao disco. Quanto maior a percentagem, menor o espaço entre os grãos e maior é a densidade do disco. Para este caso, a dureza influencia na espessura teórica máxima do cavaco, pois altera a quantidade de grãos que resulta na variação do espaçamento médio entre os grãos abrasivos. Se a estrutura do disco for “aberta” no processo de fabricação (retirando-se grãos abrasivos), deve-se adicionar maior quantidade de ligante. Para König [3] , neste caso a dureza é mantida constante, onde se observa que a porosidade é constante para cada dureza, da mesma forma que cada percentual de abrasivo é constante para cada estrutura. Para este estudo, esta afirmativa não se torna válida, pois segundo o fabricante dos discos, a dureza modifica-se quando se altera o volume de ligante no disco.

Os comportamentos descritos sobre a dureza de disco explicam a regra prática que é utilizada quando se faz necessária a escolha da dureza de um disco [7]. Para materiais duros, o disco deve ser mole, ao passo que para materiais moles o disco deve ser duro. Ao se cortar um material com alto grau de dureza, o desgaste do grão é mais intenso e torna-se desejável a auto-afiação (para que a peça não fique queimada). Além disso, o desgaste do ligante pelo cavaco não é tão evidente, uma vez que materiais duros normalmente produzem cavacos curtos e quebradiços. Já no corte de um material de baixo grau de dureza, o desgaste do grão abrasivo é mais lento e, portanto, com menor necessidade de novas camadas de grão. Soma-se a isso a possibilidade de ocorrer o surgimento de novas arestas de corte através da fratura de grãos (conforme a friabilidade do grão), e o fato de que o cavaco produzido no corte de materiais moles é, em geral, longo e dúctil, atuando com maior intensidade sobre o ligante (atrito).

Segundo Snee [6], os ensaios que envolvem discos abrasivos devem ser o mais abrangente possível e em operações que sejam largamente utilizadas. 


\section{MATERIAIS E MÉTODOS}

Os discos abrasivos ensaiados foram do tipo AR302, com escalas de dureza: normal (discos 2), 2 pontos acima (discos 3) e 2 pontos abaixo (discos 1), conforme notação apresentada pela empresa NORTON. Os corpos de prova utilizados foram barras de aço ABNT 1020 (diâmetro 5/8”).

Segundo a empresa NORTON, a especificação do disco abrasivo utilizado (AR302) indica que o grão abrasivo é de óxido de alumínio (A), ligante resinóide (R) e com duas telas (2). O código 30 é de controle interno da empresa. Este disco abrasivo é fabricado com grãos de óxido de alumínio marrom e com uma combinação de grãos com granulometria 20 e 46 mesh, para a obtenção de custo e desempenho desejados pelo mercado. Juntamente com o ligante resinóide são acrescentados enchimentos ativos, como por exemplo pirita. Embora não esteja indicada a sua dureza na especificação, trata-se de um disco abrasivo duro.

Os discos utilizados foram divididos em três lotes, com três discos cada. Os discos do lote 2 (denominados neste trabalho de discos 2) são considerados como sendo discos de dureza de grau médio, de acordo com uma tabela de dureza da estrutura dos discos abrasivos, exclusiva do fabricante. Já os discos 1 , possuem dureza de dois pontos menor na escala desta tabela, e os discos 3, têm dureza de dois pontos acima.

O cálculo de dureza através dessa tabela é baseado na retirada ou no acréscimo do ligante utilizado, o que resulta respectivamente num menor ou maior grau de dureza.

De acordo com a teoria apresentada sobre a dureza de ferramentas abrasivas, sabe-se que a proporção volumétrica deve ser mantida, respeitando-se a Equação 1. No que diz respeito a esse aspecto sabe-se que o fabricante, ao retirar ligante da estrutura desses discos abrasivos na produção dos mesmos, acrescenta grãos abrasivos na mesma proporção volumétrica, e vice-versa. Desse modo os volumes modificados são compensados por outros, considerando que o volume reservado para a porosidade é mantido constante para os três lotes.

Os parâmetros de entrada utilizados para a realização dos ensaios serão: velocidade de corte decrescente $\mathrm{Vs}=80 \mathrm{~m} / \mathrm{s}$ (inicia-se o corte com Vs, que decresce proporcionalmente à perda diametral do disco abrasivo), velocidade de mergulho do disco abrasivo na barra $\mathrm{Vf}=3,4 \mathrm{~m} / \mathrm{s}$ e as diferentes durezas dos discos abrasivos. Para cada tipo de dureza serão realizados três repetibilidades experimentais. As variáveis de saída medidas serão: força tangencial de corte média Ftcm [N], tempo de corte [s] e relação G.

\section{RESULTADOS E discusSÃo}

\subsection{Resultados para a Força Tangencial de Corte}

Na Figura 1 (a, b e c) são apresentados os resultados de força tangencial de corte média para os discos com dureza dois pontos menor, dureza normal e dureza dois pontos maior, respectivamente.

Nas legendas utilizou-se tc para o tempo de corte, o qual corresponde ao tempo total para a realização de todos os cortes.

De um modo geral, as curvas apresentam uma tendência de crescimento brusco da Ftmc até atingir um patamar elevado, onde houve uma tendência de estabilização.

Nesse caso, o patamar da Ftmc operacional ficaria muito próximo do valor inicial, o que na prática não ocorre. Observa-se que a primeira região das curvas obtidas nos ensaios com os discos 3 são mais inclinados (e mais curtos) do que os mesmos trechos para os discos 1 e 2, os quais apresentaram comportamentos semelhantes neste trecho do gráfico. Este fenômeno verificado para os discos 3 ocorre porque o crescimento da Ftmc na primeira região é somado ao fato de que os cavacos obtidos com os discos 3, por terem maior dureza, possuem maior espessura teórica do cavaco, (pelo menor do número de grãos) o que preenche os poros presentes na área de contato do disco mais rapidamente. A tendência de crescimento da Ftmc na segunda região dos gráficos (a), (b) e (c) comum entre todos os ensaios, é um aspecto esperado.

Em seguida, surge o trecho de estabilização da Ftmc (terceira região), que se mantém até o fim do ensaio. A partir desse ponto o comportamento dos gráficos da Figura 1 também é comum para todos os gráficos, pois, como os ensaios foram executados de maneira contínua, o fator temperatura somou-se, de forma preponderante, a todos os mecanismos de desgaste, resultando numa equalização da dinâmica de desgaste diametral dos discos abrasivos. 


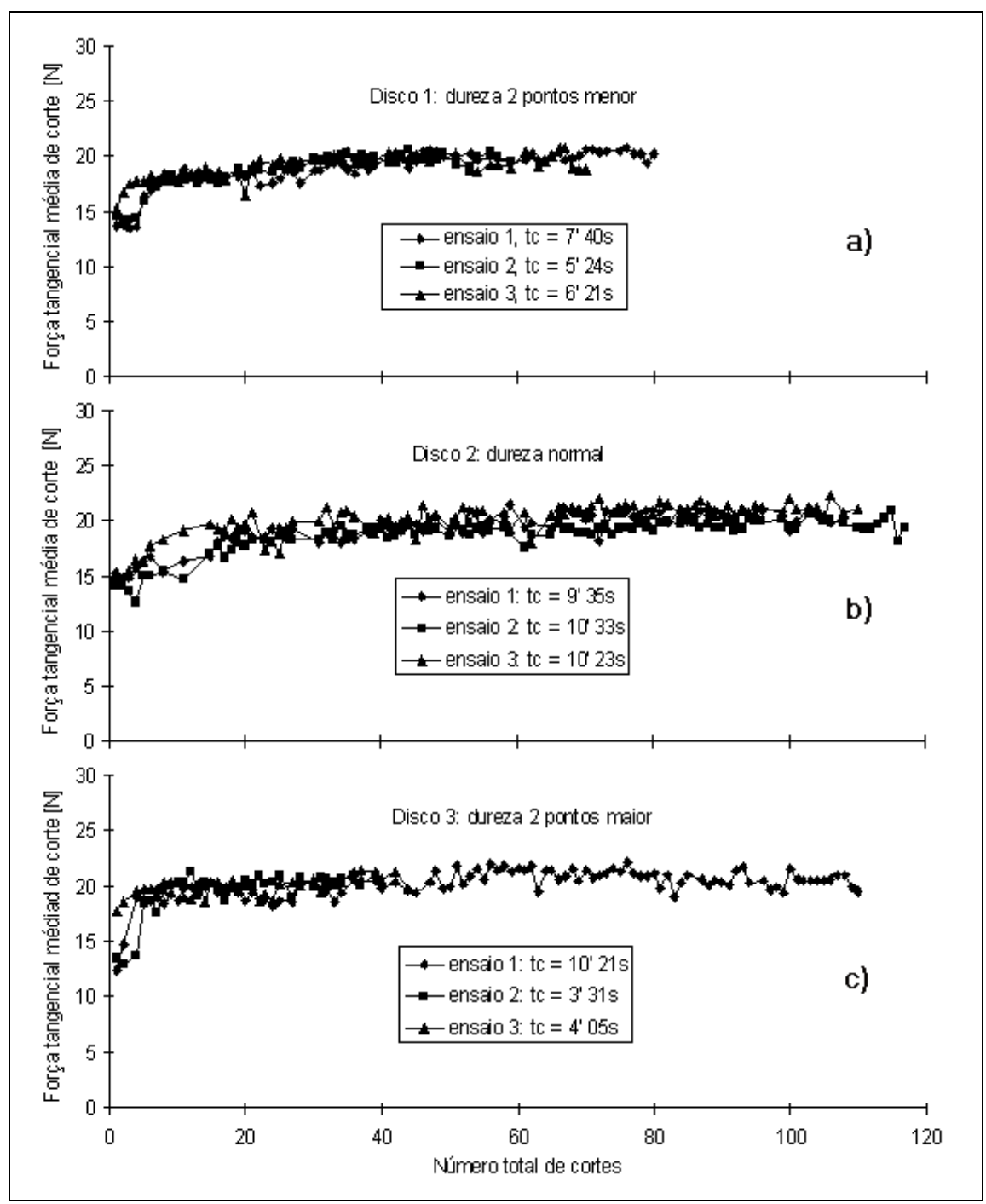

Figura 1: Resultados de força tangencial média de corte obtidos com discos de dureza: a) 2 pontos menor; b) média; e c) 2 pontos maior.

Elaborou-se um outro gráfico, que apresenta o valor médio total da força tangencial média de corte dos pontos dos gráficos anteriores. Este valor médio foi obtido através da média aritmética de todos os pontos de cada um dos três ensaios e para os três tipos de discos. Deve-se salientar que, em função da nãouniformidade dos valores iniciais de Ftmc, foram desconsiderados os vinte primeiros valores para a elaboração deste gráfico. O valor médio total da força tangencial média de corte encontrado em cada experimento é apresentado na Figura 2. Nota-se que esta força aumenta, a medida em que aumenta quantidade de ligante (maior dureza) presente em sua composição estrutural. 


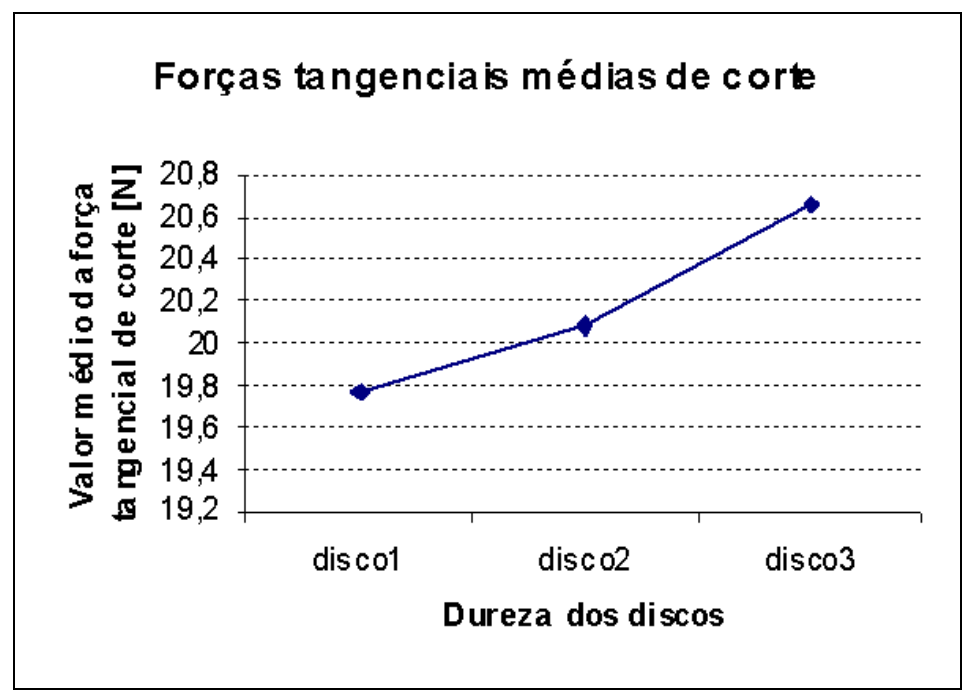

Figura 2: Valores médios totais das forças tangenciais médias dos gráficos anteriores.

Desse modo, percebe-se que a dureza do disco abrasivo influencia diretamente na força tangencial de corte necessária para se executar uma operação de corte com discos abrasivos. Neste caso, quanto maior o grau de dureza do disco abrasivo, maior o respectivo valor médio da força tangencial de corte. A variável denominada número de cortes demonstra a vida da ferramenta abrasiva, pois quanto mais peças um disco de corte cortar, maior é a vida útil deste disco.

\subsection{Resultados para a Relação G}

Uma forma prática de se avaliar o comportamento de discos abrasivos submetidos a diversas condições de corte é através da relação G. Na Figura 3 são apresentados os resultados de relação G média, em função da dureza dos três tipos de discos abrasivos estudados. Estes valores mostram que, mesmo com o crescimento da espessura teórica máxima do cavaco (em função do aumento da dureza dos discos e com a diminuição do número de grãos na estrutura dos discos), a relação $G$ tendeu a crescer. Neste caso, a ação erosiva da geometria do cavaco sobre o ligante não é tão significante, pois mesmo com a existência desse macro-desgaste, o volume crescente de ligante garante o aumento da relação G. A análise deste gráfico também foi prejudicada pelos ensaios referentes aos discos 3, pelo mesmo motivo citado no item anterior. Na Figura $3 \mathrm{Zw}$ corresponde ao volume de material removido da peça e Zs significa o volume de material desgastado do disco de corte.

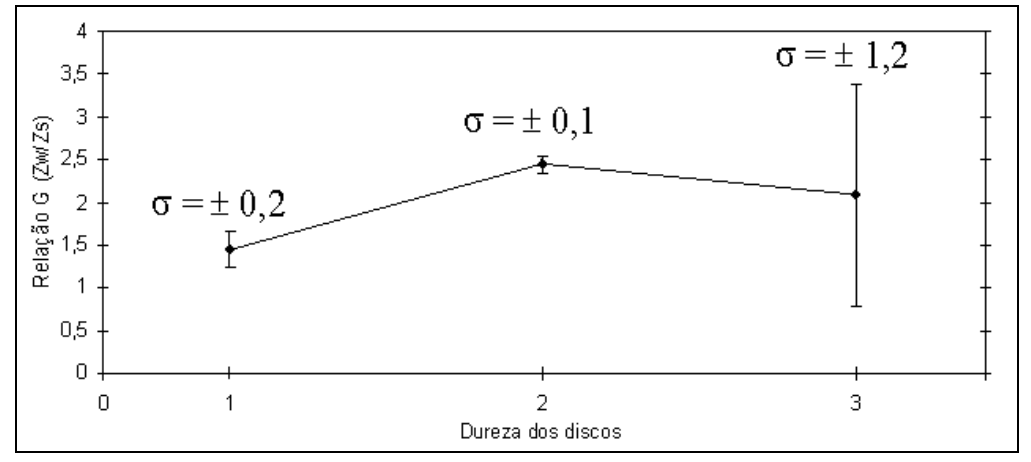

Figura 3: Dados da relação G média.

Do mesmo modo, percebe-se uma tendência de crescimento deste valor do disco 1 para o disco 2. O valor do desvio padrão para o disco 3 também foi muito elevado, o que comprova, caso não ocorressem os travamentos de dois discos de grau de dureza 3. 


\section{CONCLUSÕES}

Dos resultados obtidos pode-se concluir que:

1. os ensaios com os discos 1 e 2 apresentaram boa repetibilidade em relação a todas as variáveis de saída, com exceção dos ensaios dos discos 3, em função dos travamentos;

2. o valor médio das forças tangenciais de corte cresceu com o aumento da dureza das estruturas dos discos abrasivos de corte; número de cortes médio apresentado pelos discos abrasivos de corte estudados tendeu a crescer quando a dureza das estruturas dos mesmos aumentou;

3. a relação $G$, tendeu a crescer com o aumento da dureza da estrutura dos discos abrasivos de corte estudados, pois quanto mais ligante existe na estrutura, maiores são as seções transversais das pontes de ligação, e portanto, maior é a resistência ao macro-desgaste causado pela ação erosiva dos cavacos (que também têm suas espessuras máximas teóricas crescentes com o aumento da dureza da estrutura do disco e da redução do número de grãos) sobre o ligante.

\section{BIBLIOGRAFIA}

[1] BIANCHI, E. C., AGUIAR, P.R.., SANCHEZ, L.E.A., et al., "Otimização do Processo de Corte com Discos Abrasivos”, In: Anais do 4 Congresso Norte Nordeste de Engenharia Mecânica, pp. 301306, Recife, 1996.

[2] BIANCHI, E. C., “Estudo do Comportamento de Discos Abrasivos, em Operações do Tipo “Cut-Off” Por Mergulho Basculante, Submetidos a Diversas Condições de Corte sem Refrigeração”, Tese (LivreDocência), Faculdade de Engenharia, UNESP, Campus de Bauru, Bauru, SP, Brasil, 1997.

[3] KÖNIG, W., Fertigungsverfahren Band 2 - Schleifen, Honen, Laepten, Duesseldorf, VDI Verlag, 1980.

[4] MALKIN, S., Grinding Technology: Theory and Applications of Machining with Abrasives, England, Ellis Horwood Limited, 1989.

[5] NUSSBAUM, G.C., DICASTILHO, J.M.L., Rebolos \& Abrasivos: Tecnologia Básica, São Paulo: Ícone, 1988.

[6] SNEE, J., “Are You Making the Most of Your Cut-Off Operation?”, Welding Journal, v. 2, n. 7, pp. 6062, Feb. 1991.

[7] VIEIRA Jr., M., Avaliação da Dureza de Rebolos em Trabalho Através do Uso da Emissão Acústica na Dressagem, Tese de D.Sc., Escola de Engenharia de São Carlos, Universidade de São Paulo, São Carlos, SP, Brasil, 1996. 